\title{
Overexpression of AKT decreases the chemosensitivity of gastric cancer cells to cisplatin in vitro and in vivo
}

\author{
LING-LI ZHANG $^{1 *}$, JUN ZHANG $^{1 *}$, LEI SHEN ${ }^{1}$, XI-MING XU² and HONG-GANG YU ${ }^{1}$ \\ ${ }^{1}$ Department of Gastroenterology, Renmin Hospital of Wuhan University, Wuhan, Hubei 430060; \\ ${ }^{2}$ Department of Oncology, Renmin Hospital of Wuhan University, Wuhan, Hubei 430060, P.R. China
}

Received November 7, 2012; Accepted March 18, 2013

DOI: $10.3892 / \mathrm{mmr} .2013 .1400$

\begin{abstract}
Cisplatin (CDDP) is one of the most efficacious and widely used cytotoxic anticancer drugs used for the treatment of numerous types of cancer. However, its efficacy is limited as a result of acquired drug resistance. AKT overexpression may provide a potential mechanism leading to the resistance of human gastric cancer cells; however, the precise mechanism of the development of CDDP drug resistance remains uncertain. In the present study, we demonstrate that CDDP resistance is associated with AKT overexpression at the cellular and molecular level. We also observed that increased expression levels of AKT were sufficient to inhibit the resistance of gastric cancer cells to CDDP and that overexpressed AKT interacted with reactive oxygen species which were generated by CDDP. These results indicate that $\mathrm{AKT}$ activity is essential for the regulation of CDDP resistance in gastric cancer cells. Our results further demonstrate that AKT induces gastric cancer cells to become resistant to CDDP through the Janus kinase 2 (JAK2)/signal transducer and activator of transcription 3 (STAT3) signaling pathway. Taken together, these data support a potential role for AKT overexpression and the JAK2/STAT3 pathway in the development of CDDP drug resistance in human gastric cancer cells. We hypothesize that AKT may represent a future pharmacological target for the inhibition of CDDP resistance in human cancer.
\end{abstract}

\section{Introduction}

Gastric cancer is a prevalent health issue and remains a leading cause of cancer-related mortality worldwide (1). Cisplatin (CDDP) is an antineoplastic agent used for the treatment of

Correspondence to: Professor Hong-Gang Yu, Department of Gastroenterology, Renming Hospital of Wuhan University, No. 238 Jiefang Road, Wuhan, Hubei 430060, P.R. China

E-mail: yhgwhu@gmail.com

*Contributed equally

Abbreviations: ROS, reactive oxygen species; NAC, N-acetylcysteine Key words: chemosensitivity, AKT, gastric cancer, anticancer drugs several types of human cancer $(2,3)$, including gastric cancer. However, the efficacy of these drugs is limited by CDDP resistance. To date, a number of mechanisms have been proposed to explain CDDP resistance, including AKT overexpression (4-7). A better understanding of the processes and mechanisms leading to CDDP resistance in gastric cancer cells is necessary to develop effective therapies which may provide a pharmacological intervention for acquired CDDP resistance in cancer.

AKT is a serine/threonine kinase and consists of a family of proteins, which include AKT1, AKT2 and AKT3 (8). The AKT pathway regulates diverse cellular processes, including cell proliferation, cell cycle progression and cell survival (9). AKT is additionally important in survival when cancer cells are exposed to various stress stimuli, including cytotoxic anticancer drugs (6). Previous studies have shown that AKT hyperactivation may correlate with the resistance of cancer cells to CDDP (10-12). In the present study, we observed that AKT expression levels were significantly increased when cells were treated with CDDP. Further experiments demonstrated that AKT activation may be associated with the Janus kinase 2 (JAK2)/signal transducer and activator of transcription 3 (STAT3) pathway. The data presented in this study may provide useful information with regard to the development of potential new therapeutic approaches for the treatment of gastric cancer by targeting the JAK2/STAT3/AKT pathway to overcome CDDP resistance.

\section{Materials and methods}

Cell lines and animals. BGC823 gastric cancer cells were obtained from the Cell Bank of Chinese Academy of Sciences (Shanghai, China) and maintained in RPMI-1640 medium supplemented with $10 \%$ fetal bovine serum (FBS), $100 \mathrm{mg} / 1$ penicillin and $100 \mathrm{mg} / \mathrm{l}$ streptomycin at $37^{\circ} \mathrm{C}$ in a humidified atmosphere of $5 \% \mathrm{CO}_{2}$. The following antibodies were used: anti-AKT, anti-STAT3, anti-phospho-JAK2, anti-phosphoSTAT3, STAT3 inhibitor (Santa Cruz Biotechnology, Inc., Santa Cruz, CA, USA), anti-phospho-AKT (Millipore, Billerica, MA, USA), anti-JAK2 (Cell Signaling Technology, Inc., USA), dichlorodihydrofluorescein diacetate (DCFDA; Sigma, St. Louis, MO, USA) and N-acetylcysteine (NAC; Sigma).

A total of $9 \mathrm{BALB} / \mathrm{c}-\mathrm{nu}$ mice, 4-5 weeks old and 18-20 g in weight, provided by Beijing HFK Bioscience Co., Ltd. (Beijing, China), were bred in laminar flow cabinets and kept 
at a constant humidity and temperature $\left(25-28^{\circ} \mathrm{C}\right)$ according to standard guidelines outlined in a protocol approved by Wuhan University, Wuhan, China.

Measurement of reactive oxygen species (ROS) production. BGC823 cells were treated with CDDP for $6 \mathrm{~h}$. After washing with PBS, the cells were incubated with $33 \mathrm{mg} / \mathrm{ml}$ DCFDA in PBS for $30 \mathrm{~min}$ at $37^{\circ} \mathrm{C}$. The excess probe was washed off and the labeled cells were measured using a microscope.

JAK2 siRNA transfection. BGC823 cells were transfected with JAK2 siRNA and control siRNA (Santa Cruz Biotechnology) according to the manufacturer's instructions. Fresh medium without antibiotics was applied following $8 \mathrm{~h}$ of incubation, and following an additional $48 \mathrm{~h}$, the medium was replaced with $10 \%$ FBS, $100 \mathrm{mg} / \mathrm{l}$ penicillin and $100 \mathrm{mg} / \mathrm{l}$ streptomycin. Cell growth was maintained.

Western blot analysis. The cells were solubilized in ice-cold lysis buffer (1X PBS, 1\% Igepal CA-630, 0.5\% sodium deoxycholate, $0.1 \%$ SDS and $10 \mathrm{mg} / \mathrm{ml}$ phenylephrine). Following $30 \mathrm{~min}$ of centrifugation at $13,000 \mathrm{~g}$ at $4^{\circ} \mathrm{C}$, the supernatants were transferred to new microcentrifuge tubes and the protein concentration of the supernatant was measured using the BCA protein assay (Pierce Biotechnology, Inc., Rockford, IL, USA) and then stored at $-80^{\circ} \mathrm{C}$. Cell lysate $(50 \mu \mathrm{g})$ was separated on an SDS-polyacrylamide gel. Following SDS-PAGE, the proteins were transferred onto nitrocellulose membranes. For detection of the proteins, the membranes were blocked using $10 \%$ non-fat dry milk in Tris-buffer containing $0.1 \%$ Tween (TBS-T) and then incubated at $4^{\circ} \mathrm{C}$ overnight with anti-AKT, anti-phospho-JAK2, anti-phospho-STAT3, anti-phosphoAKT antibodies (Millipore), which were diluted in TBS-T containing $5 \%$ non-fat dry milk.

In vivo tumor growth assay. All animal experiments were conducted with the approval of the Beijing HFK Bioscience Co., Ltd. Following alcohol preparation of the skin, the nude mice (4 weeks of age) were subcutaneously inoculated with $200 \mu \mathrm{l}$ of cell suspension $\left(2 \times 10^{6}\right.$ cells $\left./ \mathrm{ml}\right)$ into the dorsal flank using a sterile 22-gauge needle. The animals were monitored daily and tumor volume $\left(\mathrm{mm}^{3}\right)$ was calculated as follows: volume $=(\text { shortest diameter })^{2} \mathrm{x}($ longest diameter $) / 2$. When the diameters of the tumors were $>10 \mathrm{~mm}$, the mice were treated by an intraperitoneal (i.p.) injection of $1 \mathrm{mg} / \mathrm{kg}$ CDDP, $2 \mathrm{~g} /$ $\mathrm{kg} \mathrm{NAC}$, and solvent once a week for 14 days. The nude mice were divided into the following groups: treated with solvent (control), CDDP and CDDP/NAC. Each group contained 3 mice. Bidimensional tumor measurements were analyzed with calipers 3 times a week; the mice were euthanized on the 7th day following drug treatment. The expression levels of AKT were examined by immunohistochemistry as previously described $(13,14)$.

Statistical analysis. Statistical analyses were performed using SPSS version 11.3 software (SPSS, Inc. Chicago, IL, USA). Values are expressed as the means \pm SD. Differences were analyzed by the $\chi^{2}$ test for incidence data and by the Student's t-test for comparison of the means. $\mathrm{P}<0.05$ was considered to indicate a statistically significant difference.
A

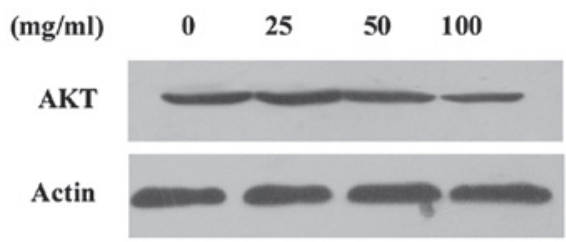

B

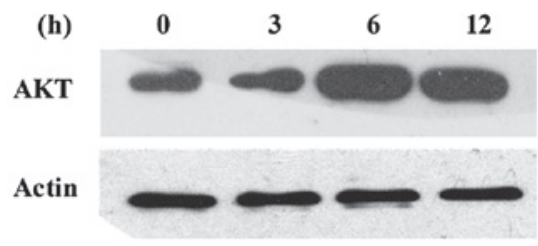

Figure 1. (A and B) Detection of AKT protein expression levels in gastric cancer cells (BGC823) by immunoblotting. Actin is used to show equal amounts of protein loading in each lane.

A

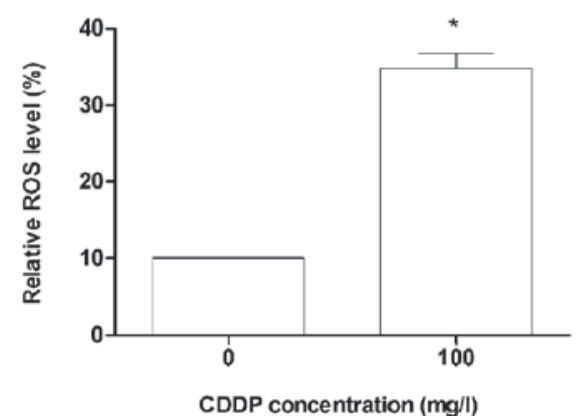

B

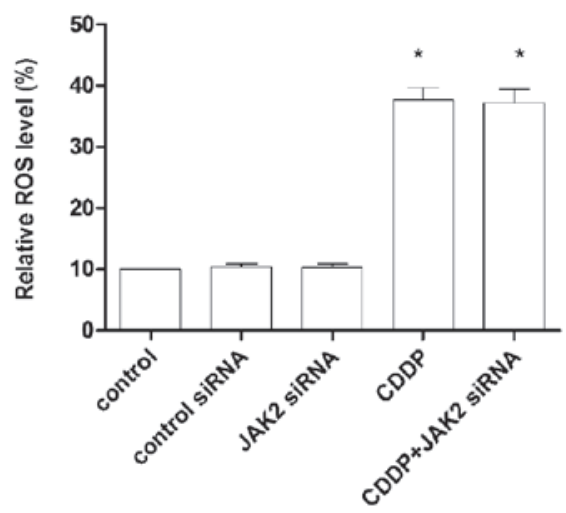

Figure 2. (A) CDDP induces ROS production. BGC823 cells were treated with $30 \mathrm{mg} / \mathrm{ml} \mathrm{CDDP}$ and the production of ROS was measured by flow cytometry. (B) BGC823 cells were treated with CDDP, control siRNA and JAK2 siRNA and the production of ROS was measured using DCFDA. ROS, reactive oxygen species; DCFDA, dichlorodihydrofluorescein diacetate; CDDP, cisplatin. ${ }^{*} \mathrm{P}<0.05$ versus control.

\section{Results}

Expression levels of AKT in gastric cancer cells. The AKT protein levels in the cancer cells were measured by western blot analysis. The cells were treated with various concentrations of CDDP for different periods of time (Fig. 1).

ROS production in gastric cancer cells. BGC823 cells were treated with $30 \mathrm{mg} / \mathrm{ml} \mathrm{CDDP}$ for $6 \mathrm{~h}$ and the production of ROS was measured by flow cytometry. (Fig. 2A). BGC823 cells were then treated with CDDP, control siRNA and JAK2 siRNA. After washing with PBS, the cells were incubated with 
A

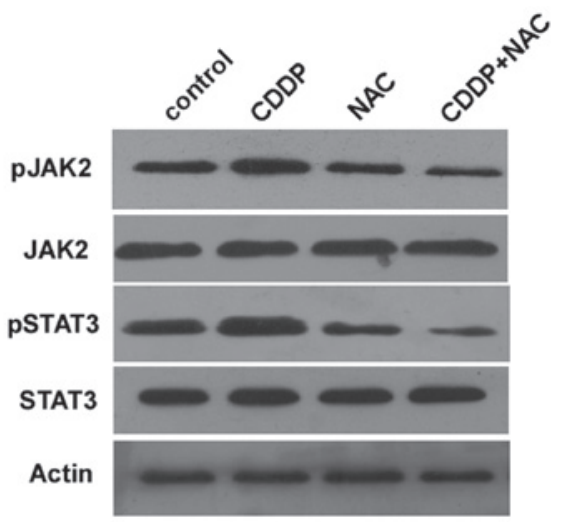

B

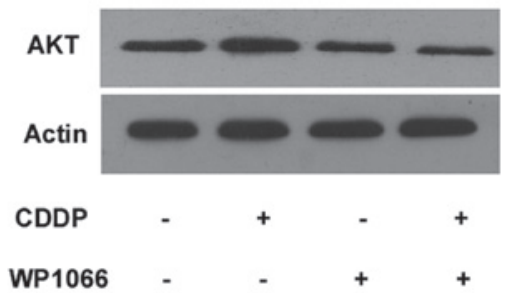

Figure 3. (A) CDDP causes the rapid tyrosine phosphorylation of JAK2 and STAT3. Growth-arrested BGC823 cells were treated with $30 \mathrm{mg} / \mathrm{ml}$ CDDP and $33 \mathrm{mg} / \mathrm{ml} \mathrm{NAC}$. Following incubation for $6 \mathrm{~h}$, western blots were probed with phosphotyrosine-specific anti-JAK2 and phosphotyrosine-specific antiSTAT3 antibodies. (B) Growth-arrested BGC823 cells were treated with $30 \mathrm{mg} / \mathrm{ml} \mathrm{CDDP}$ and $5 \mu \mathrm{M}$ WP1066 (STAT3 inhibitor). Following incubation for $12 \mathrm{~h}$, western blots were probed with anti-AKT antibody. CDDP, cisplatin; NAC, N-acetylcysteine.

A

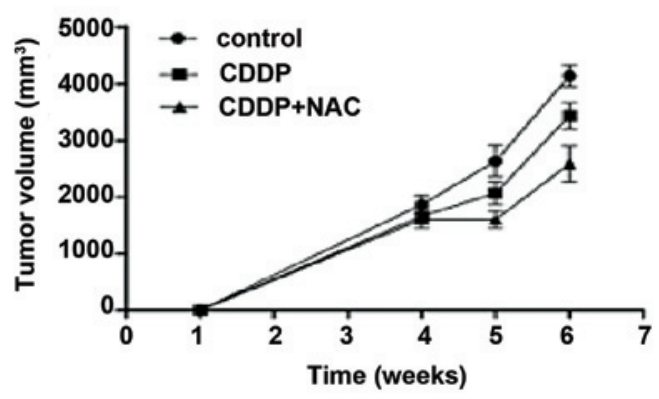

B

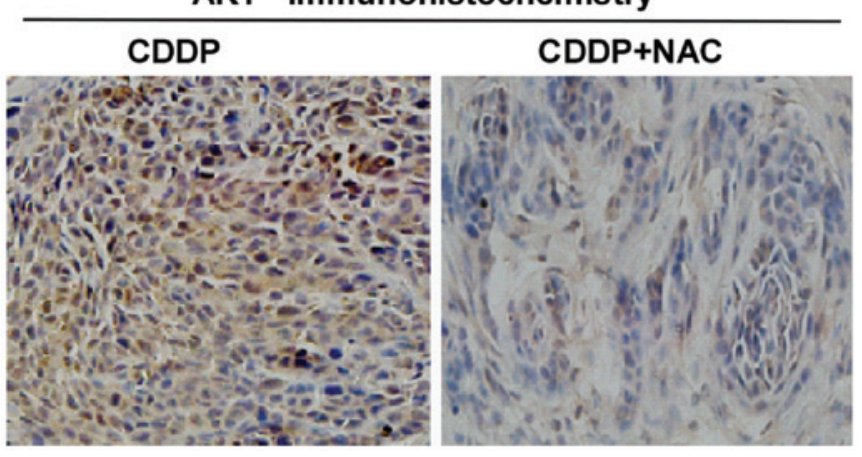

Figure 4. The mice were sacrificed and tumors were excised and photographed to measure tumor size at 6 weeks post-inoculation according to the guidance of the Animal Experimental Ethics Committee of Wuhan University. (A) Tumor sizes and tumor volumes of the nude mice in CDDP and CDDP/NAC groups. Data are presented as the means \pm SD $(n=3, P<0.05)$. (B) Immunohistochemical expression of AKT in tumors from mice treated with CDDP or CDDP/NAC. CDDP, cisplatin; NAC, N-acetylcysteine.
$33 \mathrm{mg} / \mathrm{ml}$ DCFDA in PBS for $30 \mathrm{~min}$ at $37^{\circ} \mathrm{C}$ to measure the prodution of ROS (Fig. 2B).

Effect of downregulation of the JAK2/STAT3 signaling pathway in gastric cancer cells. To determine whether the AKT-induced CDDP resistance is dependent on the activation of the JAK2/STAT3 signaling pathway, the cells were treated with $33 \mathrm{mg} / \mathrm{ml}$ NAC and $30 \mathrm{mg} / \mathrm{ml}$ CDDP. This significantly suppressed the activation of the JAK2/STAT3 signaling pathway (Fig. 3A). The expression of AKT was also decreased in the cells treated with CDDP in combination with WP1066, a STAT3 inhibitor (Fig. 3B). These results demonstrate that NAC increases the sensitivity of BGC823 cells to CDDP and that the JAK2/STAT3 pathway is involved in the AKT-induced CDDP resistance of cancer cells. Combination treatment with NAC and CDDP also decreased the levels of phospho-JAK2 and phospho-STAT3 in the BGC823 cells (Fig. 3A).

In vivo studies. Tumor development was induced by an injection of $200 \mu \mathrm{l}$ of cell suspension $\left(2 \times 10^{6}\right.$ cells $\left./ \mathrm{ml}\right)$ into the dorsal flank of athymic nude mice at 4 weeks of age. When the diameters of the tumors were $>10 \mathrm{~mm}$, the mice were treated by an intraperitoneal (i.p.) injection of $1 \mathrm{mg} / \mathrm{kg}$ CDDP, $2 \mathrm{~g} /$ $\mathrm{kg}$ NAC and solvent once a week for 14 days. The mice were sacrificed at 6 weeks post inoculation and tumors were excised and photographed to measure tumor size. The tumors from the mice treated with CDDP and NAC were significantly smaller in size compared to those from the mice treated with CDDP alone or solvent (control) (Fig. 4A). These results supported those obtained by immunohistochemistry assay, which showed that combination treatment with NAC and CDDP exerted a significantly greater inhibitory effect on AKT activation in gastric cancer cells compared to treatment with CDDP alone (Fig. 4B)

\section{Discussion}

Previous studies have demonstrated that the upregulation of AKT is a potential target for chemoresistance and AKT is overexpressed in certain types of cancer cells following treatment with CDDP (15-17). AKT is considered as an attractive target for chemotherapy and it has been postulated that the inhibition of AKT may preferentially kill cancer cells (18). Certain studies have reported the association of AKT gene amplification with drug resistance (19-22). In this study, we demonstrated that the AKT gene is amplified in BGC823 gastric cancer cells following treatment with CDDP (Fig. 1). These data suggest that the AKT gene is a potential target for CDDP resistance in BGC823 human gastric cancer cells.

The present data indicate that treatment with CDDP significantly increases AKT expression in BGC823 gastric cancer cells, as shown by western blot analysis. Furthermore, our data demonstrate that AKT expression notably reaches a plateau in BGC823 gastric cancer cells. This indicates that AKT may be a positive regulator of drug resistance in human gastric cancer cells. Previous studies have reported that CDDP is capable of inducing ROS production (16). Our results were consistent with these findings. Thus, we hypothesized that ROS may be an important component of the cellular stress signal transduction network. In the present study, we demonstrated that the inhibition of ROS activation inhibits AKT activation, 
while no changes in the levels of ROS were observed when the cells were treated with JAK2 siRNA (Fig. 2B), suggesting that the decreased expression of ROS renders AKT inactive at upstream signaling pathways. Thus, the production of ROS induced by CDDP activates AKT, thus promoting the development of resistance to chemotherapeutic agents, indicating the important role of AKT in BGC823 cells.

We also determined whether the AKT-induced CDDP resistance is dependent on the activation of the JAK2/STAT3 signaling pathway. The combined treatment of the BGC823 cells with NAC and CDDP significantly decreased the activation of the JAK2/STAT3 (Fig. 3A). In addition, AKT activation was decreased when the cells were treated with CDDP and WP1066, a STAT3 inhibitor (Fig. 3B). These results indicate that NAC increases the sensitivity of the BGC823 cells to CDDP. Thus, the JAK2/STAT3 pathway is involved in the AKT-induced CDDP resistance of cancer cells. This is consistent with AKT activation through phosphorylation that is dependent on JAK2/STAT3 activity. NAC and CDDP combination treatment decreased the levels of phospho-JAK2 and phospho-STAT3 in BGC823 cells (Fig. 3A).

However, we have not demonstrated the mechanism underlying acquired drug resistance. Evidence suggests that the JAK2/ STAT3 signaling pathway is involved in drug resistance and the regulation of AKT signaling, which may subsequently be associated with the resistance of cancer cells. By contrast, inhibiting the activity of ROS may improve the sensitivity and efficacy of chemotherapeutic drugs in the treatment of gastric cancer as it may result in the downregulation of the JAK2/STAT3 pathway and AKT, thus increasing the sensitivity of the cancer cells to treatment. Thus, it can be hypothesized that the overexpression of the AKT gene may induce drug resistance in gastric cancer via a multitude of mechanisms and AKT may be a potential molecular therapeutic target in gastric cancer.

In conclusion, our results indicate that the JAK2/STAT3 signaling pathway regulates AKT expression by ROS and is thus involved in the resistance of gastric cancer cells to chemotherapeutic agents in vitro and in vivo. The AKT gene may provide a promising therapeutic target, which may be targeted to overcome CDDP resistance in human tumors.

\section{Acknowledgements}

The authors would like to thank Mr. Hong Xia for administrative support and technical assistance in this study. This study was supported by grants from the National Natural Science Foundation of China (no. 30770967) and the Fundamental Research Funds for the Chinese Central Universities (no. 201130202020016 and no. 201130202020017).

\section{References}

1. Bonenkamp JJ, Songun I, Hermans J, Sasako M, Welvaart K, Plukker JT, van Elk P, Obertop H, Gouma DJ, Taat CW, et al: Randomised comparison of morbidity after D1 and D2 dissection for gastric cancer in 996 Dutch patients. Lancet 345: 745-748, 1995.

2. Ohtsu A, Shimada Y, Shirao K, Boku N, Hyodo I, Saito H, Yamamichi N, Miyata Y, Ikeda N, Yamamoto S, et al: Randomized phase III trial of fluorouracil alone versus fluorouracil plus cisplatin versus uracil and tegafur plus mitomycin in patients with unresectable, advanced gastric cancer: The Japan Clinical Oncology Group Study (JCOG9205). J Clin Oncol 21: 54-59, 2003.
3. Yun J, Lee J, Park SH, Park JO, Park YS, Lim HY and Kang WK: A randomised phase II study of combination chemotherapy with epirubicin, cisplatin and capecitabine (ECX) or cisplatin and capecitabine (CX) in advanced gastric cancer. Eur J Cancer 46: 885-891, 2010.

4. Chu W, Pak BJ, Bani MR, Kapoor M, Lu SJ, Tamir A, Kerbel RS and Ben-David Y: Tyrosinase-related protein 2 as a mediator of melanoma specific resistance to cis-diamminedichloroplatinum(II): therapeutic implications. Oncogene 19: 395-402, 2000.

5. Mizutani Y and Bonavida B. Overcoming cis-diamminedichloroplatinum (II) resistance of human ovarian tumor cells by combination treatment with cis-diamminedichloroplatinum (II) and tumor necrosis factor-alpha. Cancer 72: 809-818, 1993.

6. Liu LZ, Zhou XD, Qian G, Shi X, Fang J and Jiang BH: AKT1 amplification regulates cisplatin resistance in human lung cancer cells through the mammalian target of rapamycin/p70S6K1 pathway. Cancer Res 67: 6325-6332, 2007.

7. Meijer C, Mulder NH, Timmer-Bosscha H, Sluiter WJ, Meersma GJ and de Vries EG: Relationship of cellular glutathione to the cytotoxicity and resistance of seven platinum compounds. Cancer Res 52: 6885-6889, 1992.

8. Ozes ON, Mayo LD, Gustin JA, Pfeffer SR, Pfeffer LM and Donner DB: NF-kappaB activation by tumour necrosis factor requires the Akt serine-threonine kinase. Nature 401: 82-85, 1999.

9. Sarbassov DD, Guertin DA, Ali SM and Sabatini DM: Phosphorylation and regulation of Akt/PKB by the rictor-mTOR complex. Science 307: 1098-1101, 2005.

10. VanderWeele DJ, Zhou R and Rudin CM: Akt up-regulation increases resistance to microtubule-directed chemotherapeutic agents through mammalian target of rapamycin. Mol Cancer Ther 3: 1605-1613, 2004.

11. Brognard J, Clark AS, Ni Y and Dennis PA: Akt/protein kinase B is constitutively active in non-small cell lung cancer cells andpromotes cellular survival and resistance to chemotherapy and radiation. Cancer Res 61: 3986-3997, 2001

12. Falasca M: PI3K/Akt signalling pathway specific inhibitors: a novel strategy to sensitize cancer cells to anti-cancer drugs. Curr Pharm Des 16: 1410-1416, 2010.

13. Beckmann JS, Ye YZ, Anderson PG, et al: Extensive nitration of protein tyrosines in human atherosclerosis detected by immunohistochemistry. Biol Chem Hoppe Seyler 375: 81-88, 1994.

14. Liu QS, Zhang J, Liu M and Dong WG: Lentiviral-mediated miRNA against liver-intestine cadherin suppresses tumor growth and invasiveness of human gastric cancer. Cancer Sci 101: 1807-1812, 2010.

15. Page C, Lin HJ, Jin Y, Castle VP, Nunez G, Huang M and Lin J: Overexpression of Akt/AKT can modulate chemotherapyinduced apoptosis. Anticancer Res 20: 407-416, 2000.

16. Pommier Y, Sordet O, Antony S, Hayward RL and Kohn KW: Apoptosis defects and chemotherapy resistance: molecular interaction maps and networks. Oncogene 23: 2934-2949, 2004.

17. Sekharam M, Zhao H, Sun M, Fang Q, Zhang Q, Yuan Z, Dan HC, Boulware D, Cheng JQ and Coppola D: Insulin-like growth factor 1 receptor enhances invasion and induces resistance to apoptosis of colon cancer cells through the Akt/ Bcl-x(L) pathway. Cancer Res 63: 7708-7716, 2003.

18. Kandasamy K and Srivastava RK: Role of the phosphatidylinositol 3'-kinase/PTEN/Akt kinase pathway in tumor necrosis factorrelated apoptosis-inducing ligand-induced apoptosis in non-small cell lung cancer cells. Cancer Res 62: 4929-4937, 2002.

19. Liu Y, Chen L, Ko TC, Fields AP and Thompson EA: Evi1 is a survival factor which conveys resistance to both TGFbetaand taxol-mediated cell death via PI3K/AKT. Oncogene 25: 3565-3575, 2006

20. Campbell RA, Bhat-Nakshatri P, Patel NM, Constantinidou D, Ali S and Nakshatri H: Phosphatidylinositol 3-kinase/AKTmediated activation of estrogen receptor alpha: a new model for anti-estrogen resistance. J Biol Chem 276: 9817-9824, 2001.

21. Yamasaki F, Johansen MJ, Zhang D, Krishnamurthy S, Felix E, Bartholomeusz C, Aguilar RJ, Kurisu K, Mills GB, Hortobagyi GN and Ueno NT: Acquired resistance to erlotinib in A-431 epidermoid cancer cells requires down-regulation of MMAC1/PTEN and up-regulation of phosphorylated Akt. Cancer Res 67: 5779-5788, 2007.

22. Xia W, Mullin RJ, Keith BR, Liu LH, Ma H, Rusnak DW, Owens G, Alligood KJ and Spector NL: Anti-tumor activity of GW572016: a dual tyrosine kinase inhibitor blocks EGF activation ofEGFR/erbB2 and downstream Erk1/2 and AKT pathways. Oncogene 21: 6255-6263, 2002. 